\title{
Warfarin use and risk of knee and hip replacements
}

\author{
Priyanka Ballal, ${ }^{1}$ Christine Peloquin, ${ }^{1}$ Cindy Germaine Boer (D) , ${ }^{2}$ Tuhina Neogi (D) ${ }^{1}$
}

\begin{abstract}
Handling editor Josef S Smolen

- Prepublication history and additional material is published online only. To view please visit the journal online (http://dx.doi.org/10.1136/ annrheumdis-2020-219646).
\end{abstract}

${ }^{1}$ Section of Rheumatology, Department of Medicine, Boston University School of Medicine, Boston, Massachusetts, USA ${ }^{2}$ Department of Internal Medicine, Genetic Laboratories, Erasmus MC, Rotterdam, The Netherlands

\section{Correspondence to}

Dr Tuhina Neogi, Department of Rheumatology, Boston University School of Medicine, Boston, MA 2118, USA; tneogi@bu.edu

This work was presented at American College of Rheumatology (ACR) Convergence 2020 . $^{30}$

Received 2 December 2020 Revised 19 January 2021 Accepted 20 January 2021 Published Online First 3 March 2021

\section{ABSTRACT}

Background Identification of modifiable risk factors and treatments for osteoarthritis (OA) are needed. Warfarin, a vitamin $\mathrm{K}$ antagonist, causes fetal and animal model skeletal abnormalities. Vitamin $\mathrm{K}$ insufficiency has been associated with $\mathrm{OA}$, but whether warfarin is also detrimental to $O A$ is not known.

Methods We conducted a nested case-control study using a UK general practitioner electronic medical records database. We identified cases of knee or hip replacement (KR or HR) from among adults with atrial fibrillation newly prescribed either warfarin or direct oral anticoagulants (DOACs). Cases were matched with four controls by age and sex. We assessed the relation of warfarin compared with DOAC use to risk of joint replacement using conditional logistic regression. We also evaluated different durations of warfarin use. Results We identified 857 subjects with KR or HR (cases), of whom $64.6 \%$ were warfarin users, and 3428 matched controls, of whom $56.1 \%$ were warfarin users (mean age 75, 47\% female). Warfarin users had a 1.59 times higher risk of joint replacement than DOAC users (adjusted OR 1.59, 95\% Cl 1.31 to 1.92). Longer duration of warfarin use was associated with higher risk of joint replacement in comparison with $<1$ year of warfarin use.

Conclusion Warfarin, a vitamin $\mathrm{K}$ antagonist, was associated with greater risk of KR and HR (an indicator for end-stage knee OA) than DOAC use, supporting the importance of adequate vitamin $\mathrm{K}$ functioning in limiting OA progression.

\section{INTRODUCTION}

Warfarin is a commonly prescribed anticoagulant that is known to have adverse effects on the skeletal system in the context of human fetal embryopathy and in rat models characterised by abnormal skeletal mineralisation. ${ }^{1-4}$ These effects could have implications for osteoarthritis (OA), the most common form of arthritis, for which no effective treatments exist. Thus, identifying modifiable risk factors remains a high priority.

Warfarin's anticoagulant effects occur through inhibition of the functioning of vitamin $\mathrm{K}^{5}$ Vitamin K, in turn, is an essential cofactor in the post-translational gamma carboxylation of Gla proteins, a step required for these proteins to be functional. ${ }^{6}$ Gla proteins play an important role in blood coagulation, and also in the bone and cartilage, including matrix Gla protein (MGP), osteocalcin and Gas-6. ${ }^{7-9}$ Thus, warfarin's inhibition of vitamin $\mathrm{K}$ leads to inadequate functioning of Gla proteins. Low vitamin $\mathrm{K}$ status has been associated with both incidence and progression of knee OA in observational studies. ${ }^{10-13}$ Furthermore, in a

\section{Key messages}

What is already known about this subject?

- Vitamin $\mathrm{K}$ deficiency is associated with incidence and progression of osteoarthritis (OA). However, it is unclear whether vitamin $\mathrm{K}$ antagonism through warfarin is also detrimental to $\mathrm{OA}$.

\section{What does this study add?}

- In this study, use of warfarin, a vitamin $\mathrm{K}$ antagonist, was associated with greater risk of knee and hip replacement (KR and HR; an indicator for end-stage knee $\mathrm{OA}$ ) than direct oral anticoagulant (DOAC) use, suggesting that vitamin $\mathrm{K}$ antagonism may also be detrimental to $O A$.

\section{How might this impact on clinical practice or future developments? \\ - These data raise the consideration of using DOACs over warfarin when appropriately indicated in people with $O A$.}

randomised controlled trial of vitamin $\mathrm{K}$ supplementation versus placebo, those with insufficient vitamin $\mathrm{K}$ at baseline had trends towards less joint space narrowing on hand radiographs. ${ }^{14}$

Taken together, these data highlight the potentially detrimental effects of warfarin via vitamin $\mathrm{K}$ antagonism on joint tissues that could contribute to OA. We therefore sought to determine the relation of warfarin use to risk of knee and hip replacements (KR, HR), as a reflection of end-stage OA, in a large population-based cohort.

\section{METHODS}

\section{Study design}

We performed a nested case-control study using data from the IQVIA Medical Research Data (IMRD; incorporating The Health Improvement Network (THIN)). IMRD is a general practitioner (GP) electronic medical records database from the United Kingdom (UK) that is representative of the general UK population. This database has been validated for use in pharmacoepidemiological research. ${ }^{15}$

The nested case-control study was assembled from among a cohort of adults with atrial fibrillation, a common indication for long-term anticoagulation, to minimise confounding by indication. Because atrial fibrillation can be managed with warfarin or direct oral anticoagulants (DOACs), which do not antagonise vitamin $\mathrm{K},{ }^{16}$ we used an active comparator approach to further minimise 
confounding by indication. Since DOACs were first introduced to the market in the UK in 2008, we identified eligible study participants from 2009 onwards to allow time for market uptake. Study entry criteria included adults aged between 40 and 89 with atrial fibrillation who had been enrolled with a GP for at least 1 year. Participants were further required to be incident warfarin or DOAC users, defined as those who were newly prescribed an anticoagulant after 2009 , having $\geq 1$ prescription after study entry and also within 1 year before the index date (defined below) to ensure a relevant time frame of use. From among this cohort, we identified cases as those patients with KR or HR between 2014 and 2018. The index date for cases was defined as the date of surgery. Each case was matched with four controls by age and sex; if more than four controls were eligible for matching, the four controls were selected randomly. The matched controls were assigned the same index date as that of their matching case's surgery date (figure 1 ).

We excluded participants with KR or HR prior to 2014, those with warfarin or DOAC use prior to study entry (criteria defined above) and those who used both warfarin and DOAC within 1 year prior to the index date. We also excluded those with high-risk cancer (oesophageal, gastric, pancreatic and metastatic cancer), body mass index (BMI) $>40 \mathrm{~kg} / \mathrm{m}^{2}$, joint infection and oxygen therapy, as these are severe comorbidities that would limit surgical candidacy.

\section{Analytic approach}

For our primary analysis, we assessed the relation of warfarin use compared with DOAC use, both within 1 year prior to the index date, to risk of KR and HR. Because the biological effects of warfarin may become evident only after a period of use, in a secondary analysis, we assessed the relation of duration of warfarin use to risk of $\mathrm{KR}$ and $\mathrm{HR}$, defined as $\geq 4$ years, $2-<4$ years, and $1-<2$ years, compared with warfarin use of $<1$ year prior to the index date. Duration of use was calculated based on the sum of each prescription duration between study entry and the index date.

We considered the following potential confounders for adjustment in our models: BMI, renal disease, severe liver disease, prior gastrointestinal bleeding, prior intracranial haemorrhage, mitral stenosis, presence of prosthetic heart valve, prior falls, cancer, chronic obstructive pulmonary disease, dementia or cognitive impairment, diabetes, heart failure, hypertension, hyperlipidaemia, ischaemic heart disease, stroke, venous thromboembolism, medication use (antihypertensive drugs, oral hypoglycaemic drugs, insulin, lipid-lowering drugs, nonsteroidal anti-inflammatory drugs and paracetamol), GP visits and hospitalisations. Confounders were assessed by Read codes for medical conditions and with prescription records for medication. Of these, severe liver disease, prior intracranial haemorrhage, mitral stenosis and presence of prosthetic heart valve had a prevalence of $<1 \%$ and were subsequently not included

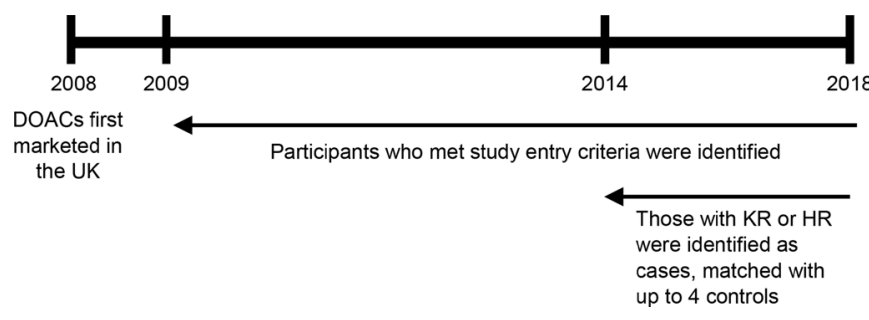

Figure 1 Study design and timeline. DOACs, direct oral anticoagulants; $H R$, hip replacement; KR, knee replacement. in multivariable adjusted models. We assessed the relation of warfarin compared with DOAC use, and duration of warfarin use, to risk of KR or HR using conditional logistic regression in separate models, adjusting for these potential confounders.

We performed two additional sensitivity analyses. Because there may be variation across GP practices in both choice of anticoagulant and referral for surgery, we matched cases and controls according to GP practice, and adjusted for age and sex in addition to the other potential confounders listed above. Each GP practice typically serves the same geographical area but could include multiple GPs. In a second set of sensitivity analyses, we repeated the primary analysis stratified by type of joint replacement, with the recognition that $97 \%$ of knee replacements are performed for knee OA, whereas hip replacements can be performed for other indications, such as hip fracture. ${ }^{17}$

\begin{tabular}{|c|c|c|}
\hline Participants & $\begin{array}{l}\text { Cases (KR/HR) } \\
(\mathrm{n}=857)\end{array}$ & $\begin{array}{l}\text { Controls } \\
(n=3428)\end{array}$ \\
\hline \multicolumn{3}{|l|}{ General demographics } \\
\hline Age (years), mean $\pm S D$ & $75.4 \pm 7.2$ & $75.4 \pm 7.2$ \\
\hline Female & $403(47.0 \%)$ & $1612(47.0 \%)$ \\
\hline BMI 25-<30 & $313(36.5 \%)$ & $1297(37.8 \%)$ \\
\hline $\mathrm{BMI} \geq 30$ & $365(42.6 \%)$ & $1088(31.7 \%)$ \\
\hline \multicolumn{3}{|l|}{ Comorbidities } \\
\hline Cancer & $154(18.0 \%)$ & $648(18.9 \%)$ \\
\hline COPD & $214(25.0 \%)$ & $825(24.1 \%)$ \\
\hline Dementia/cognitive impairment & $6(0.7 \%)$ & $106(3.1 \%)$ \\
\hline Diabetes & $170(19.8 \%)$ & $782(22.8 \%)$ \\
\hline Heart failure & $113(13.2 \%)$ & $600(17.5 \%)$ \\
\hline Hyperlipidaemia & $153(17.9 \%)$ & $702(20.5 \%)$ \\
\hline Hypertension & $590(68.8 \%)$ & $2303(67.2 \%)$ \\
\hline IHD & $191(22.3 \%)$ & $959(28.0 \%)$ \\
\hline Mitral stenosis & $8(0.9 \%)$ & $17(0.5 \%)$ \\
\hline Prior falls & $153(17.9 \%)$ & $576(16.8 \%)$ \\
\hline Prior GI bleeding & $26(3.0 \%)$ & $98(2.9 \%)$ \\
\hline Prior intracranial haemorrhage & $4(0.5 \%)$ & $37(1.1 \%)$ \\
\hline Prosthetic valve & $3(0.4 \%)$ & $6(0.2 \%)$ \\
\hline Renal disease (CKD 1-3) & $203(23.7 \%)$ & $895(26.1 \%)$ \\
\hline Renal disease (CKD 4-5 and renal transplant) & $10(1.2 \%)$ & $54(1.6 \%)$ \\
\hline Severe liver disease & $5(0.6 \%)$ & $17(0.5 \%)$ \\
\hline Stroke & $135(15.8 \%)$ & $702(20.5 \%)$ \\
\hline Venous thromboembolism & $36(4.2 \%)$ & $154(4.5 \%)$ \\
\hline \multicolumn{3}{|l|}{ Medication use } \\
\hline Antihypertensive drugs & $775(90.4 \%)$ & $3076(89.7 \%)$ \\
\hline Insulin & $13(1.5 \%)$ & $110(3.2 \%)$ \\
\hline Lipid-lowering drugs & $492(57.4 \%)$ & $2090(61.0 \%)$ \\
\hline NSAIDs & $337(39.3 \%)$ & $1275(37.2 \%)$ \\
\hline Oral hypoglycaemic drugs & $87(10.2 \%)$ & $463(13.5 \%)$ \\
\hline Paracetamol & $581(67.8 \%)$ & $1340(39.1 \%)$ \\
\hline \multicolumn{3}{|c|}{ GP visits (assessed within 1 year before first warfarin/DOAC prescription) } \\
\hline $0-5$ & $330(38.5 \%)$ & $1606(46.8 \%)$ \\
\hline$>5$ & $527(61.5 \%)$ & $1822(53.2 \%)$ \\
\hline \multicolumn{3}{|c|}{ Hospitalisations (assessed within 1 year before first warfarin/DOAC prescription) } \\
\hline $0-2$ & $820(95.7 \%)$ & $3189(93.0 \%)$ \\
\hline$\geq 3$ & $37(4.3 \%)$ & $239(7.0 \%)$ \\
\hline
\end{tabular}

Results are shown as N (\%) unless stated otherwise.

$\mathrm{BMI}$, body mass index; CKD, chronic kidney disease; COPD, chronic obstructive pulmonary disease; DOAC, direct oral anticoagulant; GI, gastrointestinal; GP, general practitioner; $H R$, hip replacement; IHD, ischaemic heart disease; $K R$, knee replacement; NSAIDs, non-steroidal anti-inflammatory drugs. 
Table 2 Warfarin use and risk of knee and hip replacements

\begin{tabular}{|c|c|c|}
\hline $\begin{array}{l}\text { A. Warfarin versus DOAC use } \\
\text { within } 1 \text { year of index date, } \\
\text { regardless of duration }\end{array}$ & Cases (KR/HR) & Controls \\
\hline articipants (n) & 857 & 3428 \\
\hline Varfarin use & $554(64.6 \%)$ & $1923(56.1 \%)$ \\
\hline OAC use & $303(35.4 \%)$ & $1505(43.9 \%)$ \\
\hline $\begin{array}{l}\text { Ddds ratio }(95 \% \mathrm{Cl}) \text {, matched by age } \\
\text { and gender }\end{array}$ & 1.57 (1.32 to 1.86$)$ & \\
\hline Adjusted* odds ratio $(95 \% \mathrm{Cl})$ & 1.59 (1.31 to 1.92$)$ & \\
\hline $\begin{array}{l}\text { B. Warfarin versus DOAC use, } \\
\text { matched by practice }\end{array}$ & Cases (KR/HR) & Controls \\
\hline Participants (n) & 857 & 3422 \\
\hline Narfarin use & $554(64.6 \%)$ & $2077(60.7 \%)$ \\
\hline OAC use & $303(35.4 \%)$ & $1345(39.3 \%)$ \\
\hline dds ratio $(95 \% \mathrm{Cl})$, matched by practice & 1.25 (1.05 to 1.50$)$ & \\
\hline Adjustedt odds ratio $(95 \% \mathrm{Cl})$ & 1.36 (1.11 to 1.66$)$ & \\
\hline $\begin{array}{l}\text { C. Warfarin versus DOAC use, } \\
\text { stratified by anatomic location of } \\
\text { joint replacement }\end{array}$ & Cases (KR only) & Controls \\
\hline Participants (n) & 497 & 1988 \\
\hline Narfarin use & $324(65.2 \%)$ & $1139(57.3 \%)$ \\
\hline OAC use & $173(34.8 \%)$ & $849(42.7 \%)$ \\
\hline $\begin{array}{l}\text { dds ratio }(95 \% \mathrm{Cl}) \text {, matched by age } \\
\text { and gender }\end{array}$ & 1.52 (1.21 to 1.92$)$ & \\
\hline \multirow[t]{2}{*}{ Adjusted* odds ratio $(95 \% \mathrm{Cl})$} & 1.58 (1.22 to 2.04$)$ & \\
\hline & Cases (HR only) & Controls \\
\hline articipants (n) & 485 & 1940 \\
\hline Narfarin use & $304(62.7 \%)$ & $1129(58.2 \%)$ \\
\hline OAC use & $181(37.3 \%)$ & $811(41.8 \%)$ \\
\hline $\begin{array}{l}\text { dds ratio }(95 \% \mathrm{Cl}) \text {, matched by age } \\
\text { and gender }\end{array}$ & $1.27(1.01$ to 1.60$)$ & \\
\hline Idjusted* odds ratio $(95 \% \mathrm{Cl})$ & 1.33 (1.03 to 1.72$)$ & \\
\hline
\end{tabular}

${ }^{*}$ Adjusted for the same variables as in table 1 excluding age and sex, which were matching variables.

†Adjusted for age and gender in addition to variables in table 1.

DOAC, direct oral anticoagulant; HR, hip replacement ; KR, Knee replacement.

\section{Patient and public involvement}

Patients and the public were not involved in this study.

\section{RESULTS}

We identified 857 cases with KR or HR and matched them to 3428 controls. The mean age of both groups was 75 years and $47 \%$ were female. Other baseline characteristics are listed in table 1. Notable differences in comorbidities included a higher prevalence of diabetes, heart failure, stroke and ischaemic heart disease among controls, probably because individuals with these comorbidities were less likely to be surgical candidates. As expected, obesity (BMI $\geq 30$ ) was more commonly seen among cases $(42.6 \%$ vs $31.7 \%)$.

Of the 857 cases, $64.6 \%$ were warfarin users and the remaining $35.4 \%$ were DOAC users. Among the 3428 controls, 56.1\% were warfarin users and $43.9 \%$ were DOAC users. Warfarin use was associated with $59 \%$ higher risk of having a KR or HR than DOAC use (adjusted OR 1.59, 95\% CI 1.31 to 1.92; table 2A).

Longer durations of warfarin were associated with higher risk of KR or HR compared with < 1 year of warfarin use (figure 2 and online supplemental table 1). Participants with warfarin use for $\geq 4$ years had $86 \%$ higher risk of KR or HR compared with new warfarin users ( $<1$ year) $(95 \%$ CI 1.35 to 2.57 ).
When analyses were repeated with matching by GP practice, the magnitude of the association was slightly diminished but remained statistically significant (adjusted OR 1.36, 95\% CI 1.11 to 1.66) (table 2B). When we stratified analyses by type of joint replacement (knee or hip), the results were similar to the primary analysis for KRs, and slightly diminished for HRs. Warfarin use was associated with $58 \%$ higher risk of KR $(95 \% \mathrm{CI}$ 1.22 to 2.04$)$ and $33 \%$ higher risk of HR (95\% CI 1.03 to 1.72$)$ compared with DOAC users (table 2C).

\section{DISCUSSION}

In this population-based case-control study of older adults with atrial fibrillation, warfarin use was associated with a higher risk of knee and hip replacements, an indicator of end-stage OA, compared with DOAC use. Furthermore, longer duration of warfarin use was associated with greater risk of joint replacement compared with shorter duration of its use.

The mechanism for this observed association of warfarin on risk of end-stage $\mathrm{OA}$ as assessed by joint replacement is probably related to warfarin's role as a vitamin $\mathrm{K}$ antagonist. Warfarin's antagonism of vitamin K would be expected to recapitulate effects of insufficient vitamin K. Because vitamin K confers functionality to Gla proteins through gamma-carboxylation, insufficient vitamin $\mathrm{K}$ or inhibition of vitamin K's functioning through warfarin leads to undercarboxylation of vitamin K-dependent proteins, limiting their functionality. An important vitamin K-dependent protein that has been specifically linked to abnormalities in soft tissue mineralisation and OA is MGP. Genetic deficiencies of MGP in humans, known as Keutel syndrome, and in transgenic mice result in cartilage calcification, highlighting the role of MGP as an inhibitor of mineralisation. ${ }^{18-21}$ Of specific

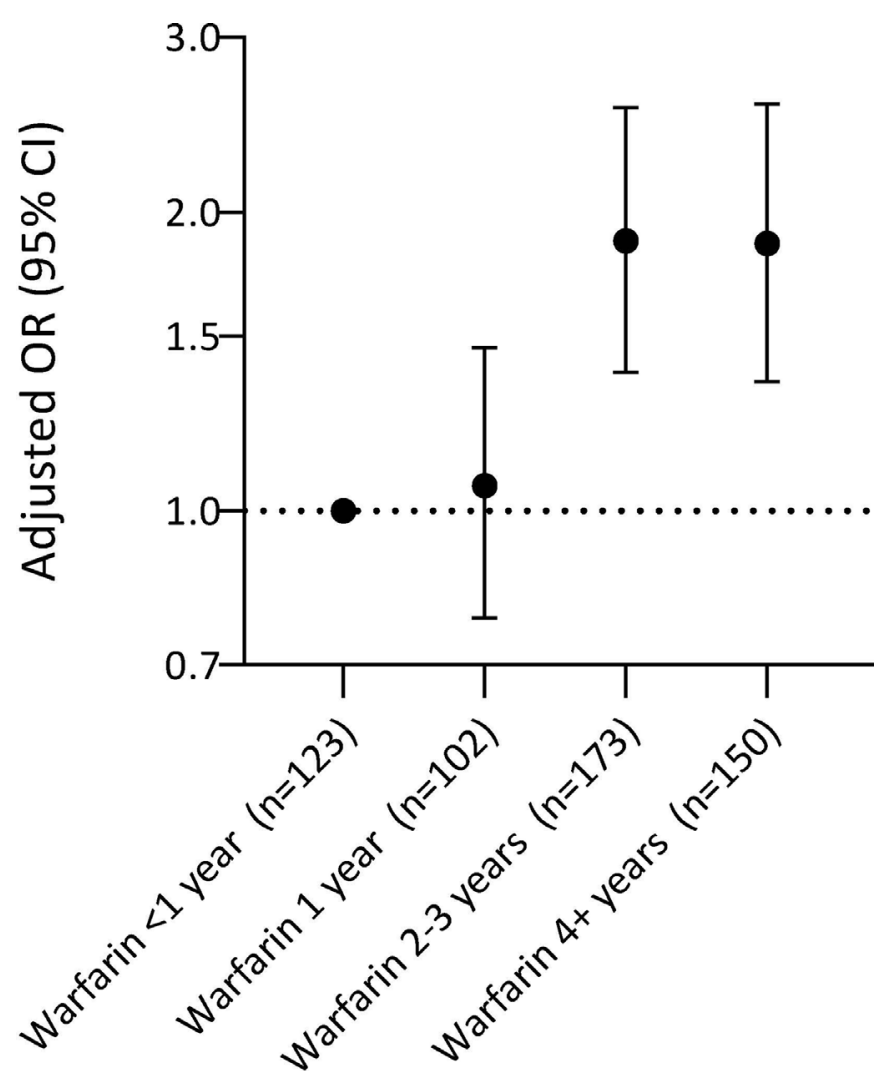

Figure 2 The relation of duration of warfarin use to risk of knee or hip replacement. Analyses adjusted for potential confounders in table 1, with the exception of age and sex, which were matching variables. 
relevance to OA, MGP is primarily uncarboxylated in human OA cartilage, whereas it is primarily carboxylated (and therefore functional) in healthy cartilage. ${ }^{22}$ Furthermore, a genome-wide association study identified coding variants of $M G P$ as associated with hand OA, and complementary functional studies demonstrated that MGP RNA expression of the hand OA allele was higher than that of the reference allele in human OA cartilage. ${ }^{23}$ These findings complemented a smaller study that also identified MGP single nucleotide polymorphism in hand OA. ${ }^{24}$ Thus, the detrimental effects of warfarin through inhibition of vitamin K's activities may be further exacerbated in those with genetic polymorphisms of MGP.

Our results add to the existing literature, extending insights into the importance of vitamin $\mathrm{K}$ and its dependent proteins in OA. Low levels of plasma phylloquinone, the major form of circulating vitamin $\mathrm{K}$, were associated with prevalence of both radiographic hand and knee OA in the Framingham Offspring cohort, while low dietary vitamin $\mathrm{K}$ intake was associated with radiographic knee OA in a Japanese population-based cohort. ${ }^{10} 11$ Complementing those radiographic findings, two longitudinal studies also demonstrated an association of low plasma phylloquinone with incidence ${ }^{12}$ and progression $^{13}$ of cartilage lesions on knee MRI, providing more direct support for a role of vitamin $\mathrm{K}$ in cartilage pathology. To more definitively evaluate the role of vitamin $\mathrm{K}$ in $\mathrm{OA}$, a randomised controlled trial of vitamin $\mathrm{K}$ supplementation versus placebo was conducted in 378 participants who were enrolled without regards to their baseline vitamin $\mathrm{K}$ status. There was no difference overall in the prevalence of hand OA between the two arms. ${ }^{14}$ However, in a post hoc analysis limited to patients who were vitamin $\mathrm{K}$ insufficient at baseline, those in the vitamin $\mathrm{K}$ supplementation arm had $47 \%$ significantly less joint space narrowing than those receiving placebo, suggesting that for hand $\mathrm{OA}$ those with insufficient vitamin $\mathrm{K}$ could derive benefit from vitamin $\mathrm{K}$ supplementation. ${ }^{14}$

In addition to vitamin K's role in OA through Gla proteins in the bone and cartilage, it might have direct effects on inflammation, which could have relevance for OA. ${ }^{25}$ Higher plasma phylloquinone was associated with lower inflammatory burden in two separate cohorts cross-sectionally. ${ }^{2627}$ In contrast, undercarboxylated osteocalcin, a Gla protein, was not associated with inflammation. ${ }^{26}$ Since these effects appear to be unrelated to vitamin K's role in gamma-carboxylation, it is unlikely that warfarin would play a role in vitamin K's effects on inflammation. ${ }^{28}$ Thus, there might be potential additional benefit to targeting vitamin $\mathrm{K}$ in OA beyond warfarin alone.

We recognise that this observational study cannot provide definitive causal insights. However, it is unlikely that a randomised trial of warfarin versus a DOAC for an OA end point would be performed. We dealt with confounding by indication by limiting our sample to adults with atrial fibrillation as this diagnosis warrants anticoagulation, and by including an active comparator arm of DOACs, which are anticoagulants used for the same indication but do not antagonise vitamin K. Our study also has limitations. As with all observational studies, there is potential for residual confounding. We identified exposure to warfarin and DOACs through prescriptions, but these do not necessarily reflect medication adherence. Joint replacement was used as a proxy for end-stage OA. While approximately 97\% of KRs are performed for knee OA, HRs can be performed for other reasons, such as hip fracture. ${ }^{17}$ We are unable to disentangle putative effects of warfarin on bone density and risk of osteoporotic fracture ${ }^{29}$ versus end-stage $\mathrm{OA}$ as the reason for HR in this study. Nonetheless, in stratified analyses, warfarin use was associated with risk of KR with a similar magnitude as in the main analysis, and with HR, though with a slightly lower magnitude. Overall, our study provides support for a detrimental effect of warfarin in OA, complementing prior studies examining the effects of vitamin $\mathrm{K}$ in $\mathrm{OA}$, and supports the inference that warfarin's effects are due to its role as a vitamin K antagonist.

Given the worldwide prevalence and impact of OA and lack of effective disease-modifying therapies, our study supports the need for a well-powered randomised control trial evaluating vitamin $\mathrm{K}$ supplementation in OA. Our study also raises the consideration of preferentially using DOACs rather than warfarin, when appropriately indicated, in people with OA.

Twitter Priyanka Ballal @PriBallal, Cindy Germaine Boer @CurlyGeneticist and Tuhina Neogi @Tuhina_Neogi

Contributors PB was involved in study design, code selections, drafting the manuscript and critical revision. CP was involved in study design, data analysis and critical revision. CGB was involved in critical revision. TN was involved in conception, study design, data analysis, critical revision and final approval of the manuscript.

Funding This work and CP were supported by NIH P30AR072571. TN was supported by NIH K24AR070892. Sponsors played no role in the conduct of the study or preparation of this manuscript.

Competing interests None declared.

Patient consent for publication Not required.

Ethics approval Boston University Medical Campus Institutional Review Board (protocol H-32821).

Provenance and peer review Not commissioned; externally peer reviewed.

Data availability statement Data may be obtained from a third party and are not publicly available. Deidentified data were used for this work. The IMRD dataset used in this work is a subscription-based dataset with a legal contract requiring data to remain onsite and analysed at Boston University Medical Center. We are therefore legally unable to make these data publicly available. We would be able to collaborate with potential external investigators to deal with research questions of interest if appropriate resources are provided. Investigators may contact IMRD for further information about obtaining data.

Supplemental material This content has been supplied by the author(s). It has not been vetted by BMJ Publishing Group Limited (BMJ) and may not have been peer-reviewed. Any opinions or recommendations discussed are solely those of the author(s) and are not endorsed by BMJ. BMJ disclaims all liability and responsibility arising from any reliance placed on the content. Where the content includes any translated material, BMJ does not warrant the accuracy and reliability of the translations (including but not limited to local regulations, clinical guidelines, terminology, drug names and drug dosages), and is not responsible for any error and/or omissions arising from translation and adaptation or otherwise.

\section{ORCID iDs}

Cindy Germaine Boer http://orcid.org/0000-0003-4809-0044

Tuhina Neogi http://orcid.org/0000-0002-9515-1711

\section{REFERENCES}

1 Price PA, Williamson MK, Haba T, et al. Excessive mineralization with growth plate closure in rats on chronic warfarin treatment. Proc Natl Acad Sci U SA 1982;79:7734-8.

2 Haffa A, Krueger D, Bruner J, et al. Diet- or warfarin-induced vitamin K insufficiency elevates circulating undercarboxylated osteocalcin without altering skeletal status in growing female rats. J Bone Miner Res 2000;15:872-8.

3 Feteih R, Tassinari MS, Lian JB. Effect of sodium warfarin on vitamin K-dependent proteins and skeletal development in the rat fetus. J Bone Miner Res 1990;5:885-94

4 Hall JG, Pauli RM, Wilson KM. Maternal and fetal sequelae of anticoagulation during pregnancy. Am J Med 1980;68:122-40.

5 Hirsh J, Fuster V, Ansell J, et al. American Heart Association/American College of Cardiology Foundation guide to warfarin therapy. Circulation 2003;107:1692-711.

6 Furie B, Bouchard BA, Furie BC. Vitamin K-dependent biosynthesis of gammacarboxyglutamic acid. Blood 1999:93:1798-808.

7 Hauschka PV, Lian JB, Cole DE, et al. Osteocalcin and matrix Gla protein: vitamin K-dependent proteins in bone. Physiol Rev 1989;69:990-1047.

8 Loeser RF, Varnum BC, Carlson CS, et al. Human chondrocyte expression of growtharrest-specific gene 6 and the tyrosine kinase receptor Axl: potential role in autocrine signaling in cartilage. Arthritis Rheum 1997;40:1455-65.

9 Price PA. Gla-containing proteins of bone. Connect Tissue Res 1989;21:51-60.

10 Neogi T, Booth SL, Zhang YQ, et al. Low vitamin K status is associated with osteoarthritis in the hand and knee. Arthritis Rheum 2006;54:1255-61. 
11 Oka H, Akune T, Muraki S, et al. Association of low dietary vitamin $\mathrm{K}$ intake with radiographic knee osteoarthritis in the Japanese elderly population: dietary survey in a population-based cohort of the road study. J Orthop Sci 2009;14:687-92.

12 Misra D, Booth SL, Tolstykh I, et al. Vitamin K deficiency is associated with incident knee osteoarthritis. Am J Med 2013;126:243-8.

13 Shea MK, Kritchevsky SB, Hsu F-C, et al. The association between vitamin K status and knee osteoarthritis features in older adults: the health, aging and body composition study. Osteoarthritis Cartilage 2015;23:370-8.

14 Neogi T, Felson DT, Sarno R, et al. Vitamin K in hand osteoarthritis: results from a randomised clinical trial. Ann Rheum Dis 2008;67:1570-3.

15 Denburg MR, Haynes K, Shults J, et al. Validation of the health improvement network (THIN) database for epidemiologic studies of chronic kidney disease. Pharmacoepidemiol Drug Saf 2011;20:1138-49.

16 Murawski MM, Miederhoff P, Rule W. Birth order and communication skills of pharmacy students. Percept Mot Skills 1995;80:891-5.

17 Mears SC. Classification and surgical approaches to hip fractures for nonsurgeons. Clin Geriatr Med 2014:30:229-41.

18 Luo G, Ducy P, McKee MD, et al. Spontaneous calcification of arteries and cartilage in mice lacking matrix Gla protein. Nature 1997:386:78-81.

19 El-Maadawy S, Kaartinen MT, Schinke T, et al. Cartilage formation and calcification in arteries of mice lacking matrix Gla protein. Connect Tissue Res 2003;44 Suppl 1:272-8.

20 Hur DJ, Raymond GV, Kahler SG, et al. A novel MGP mutation in a consanguineous family: review of the clinical and molecular characteristics of Keutel syndrome. $A m J$ Med Genet A 2005;135:36-40.

21 Munroe PB, Olgunturk RO, Fryns JP, et al. Mutations in the gene encoding the human matrix Gla protein cause Keutel syndrome. Nat Genet 1999;21:142-4.
22 Wallin R, Schurgers LJ, Loeser RF. Biosynthesis of the vitamin K-dependent matrix Gla protein (MGP) in chondrocytes: a fetuin-MGP protein complex is assembled in vesicles shed from normal but not from osteoarthritic chondrocytes. Osteoarthritis Cartilage 2010;18:1096-103.

23 den Hollander W, Boer CG, Hart DJ, et al. Genome-wide association and functional studies identify a role for matrix Gla protein in osteoarthritis of the hand. Ann Rheum Dis 2017;76:2046-53.

24 Misra D, Booth SL, Crosier MD, et al. Matrix Gla protein polymorphism, but not concentrations, is associated with radiographic hand osteoarthritis. J Rheumatol 2011;38:1960-5.

25 Greene MA, Loeser RF. Aging-related inflammation in osteoarthritis. Osteoarthritis Cartilage 2015;23:1966-71.

26 Shea MK, Booth SL, Massaro JM, et al. Vitamin K and vitamin D status: associations with inflammatory markers in the Framingham Offspring Study. Am J Epidemiol 2008:167:313-20.

27 Shea MK, Cushman M, Booth SL, et al. Associations between vitamin K status and haemostatic and inflammatory biomarkers in community-dwelling adults. The multiethnic study of atherosclerosis. Thromb Haemost 2014;112:438-44.

28 Harshman SG, Shea MK. The role of vitamin K in chronic aging diseases: inflammation, cardiovascular disease, and osteoarthritis. Curr Nutr Rep 2016:5:90-8.

29 Lutsey PL, Norby FL, Ensrud KE, et al. Association of anticoagulant therapy with risk of fracture among patients with atrial fibrillation. JAMA Intern Med 2020;180:245-53.

30 Ballal P, Peloquin C, Cindy B. Warfarin use and risk of knee and hip replacements [abstract]. Arthritis Rheumatol 2020;72 https://acrabstracts.org/abstract/warfarin-useand-risk-of-knee-and-hip-replacements/ 